\title{
AN ALTERNATIVE MODEL FOR OPTIMISING PAYLOADS OF BUILDING GLASS
}

\author{
H.A. Taha \\ Department of Industrial Engineering \\ University of Arkansas, U.S.A. \\ hat@uark.edu
}

\begin{abstract}
This article deals with the development of a multi-stage model for optimising payload placement on a hauler-trailer rig in an environment described by physical and regulatory constraints. The model which purports to be an improvement on an earlier model provides two types of solution i.e. a feasible solution which satisfies all zone loading and axle weight constraints, or an infeasible solution giving the cause and quantification of source(s) of infeasibility which may be used to modify model inputs for further attempts at optimisation.
\end{abstract}

\section{OPSOMMING}

Die artikel handel oor die ontwikkeling van 'n multistadiummodel vir die optimisering van vragplasing op 'n sleepwa onder fisiese en regsvoorskriftelike voorwaardes. Die model wat daarop aanspraak maak dat dit 'n verbetering is op 'n vorige model, lewer as uitset twee oplossingstipes naamlik 'n gangbare oplossing wat alle sone- en aslasrandvoorwaardes eerbiedig, of 'n ongangbare oplossing wat oorsaak en kwantifisering van ongangbaarheidsbronne uitwys vir die gebruik van gewysigde modelinsette by verdere pogings tot optimisering. 


\section{INTRODUCTION}

Brits and Conradie [1] developed a rather intriguing model for optimising payloads at PFG Building Glass. It deals with the use of specially equipped (fifth-wheel) trailers to deliver packs of sheets of flat glass to customers. These packs vary in both size and weight, and a single trailer load may include different packs depending on the orders received. The length of the trailer is divided into zones with variable boundaries depending on the type of glass being transported. Each zone includes an equal number of left and right slots along the width of the trailer with each slot designed to hold one glass pack. Government regulations limit the weights allowed at the axles of the hauler and the trailer to preset safe limits. Weights on the axles are directly related to the actual positioning of glass packs on the trailer. The optimisation model developed by Brits and Conradie advances a solution that determines the exact trailer slots where glass packs must be loaded. The model uses a binary variable, $x_{i j k}$, that assumes the value 1 if a pack of type $i$ is loaded in slot $j$ of zone $k$. Optimisation calls for minimizing a linear objective function whose coefficients are the product of the weight of the pack and a factor that loads the packs as close as possible to the centre slots in each zone to prevent tipping. The constraints eliminate the possibility of conflicts in loading as well as accounting for the specifications and number of glass packs. Once the solution $x_{i j k}$ is determined, the resulting weights on the three axles are computed. The solution is feasible if regulations are met. Else, changes in the order mix are made with the goal of eliminating infeasibility.

Brits and Conradie's model has a number of drawbacks:

1. The logic for the development of the objective function is counter-intuitive because, in effect, it minimizes the total weight of glass packs to be loaded on the trailer. (The use of the modifying factor to force loading the packs toward the centre is secondary in this case.)

2. Axle forces play a passive role in the optimisation model, in the sense that no attempt is made to determine the loading process in a manner that minimizes weights on the axle.

3. The article solves the model by converting a perfectly linear integer linear program into a nonlinear one with the claim that the nonlinear model is "easier to read."

This article proposes an alternative optimisation model that alleviates these drawbacks. Because our development deals directly with the three-dimensional integer program, there is a need to establish a consistent notation throughout the article. For this reason, the presentation is self-contained, in the sense that it includes Brits and Conradie's use of a free body diagram to calculate forces. The author wishes to acknowledge the contribution of Brits and Conradie as a fundamental asset in the development of this work.

\section{DESCRIPTION OF THE PGF PROBLEM:}

Figure 1 provides a schematic of a typical hauler-trailer rig with its axles located at points $A$, $B$, and $C$. Government regulations set maximum limits on load at each axle. As such, the actual positioning of the packs on the trailer is crucial in determining these weights. Heavier packs placed toward the front of the trailer increases the load on the hauler axles B and C. 
The opposite is true, in the sense that load increase is shifted to trailer axle A if heavier packs are placed toward the rear of the trailer. The problem thus calls for determining the location of packs on the trailer bed to satisfy axle load limits. Of course, the order mix may be such that load limits may be exceeded. In such cases, the solution should provide information regarding excess weight on each axle with the objective of modifying the order mix and securing a new solution. The process is repeated until load limits are met.
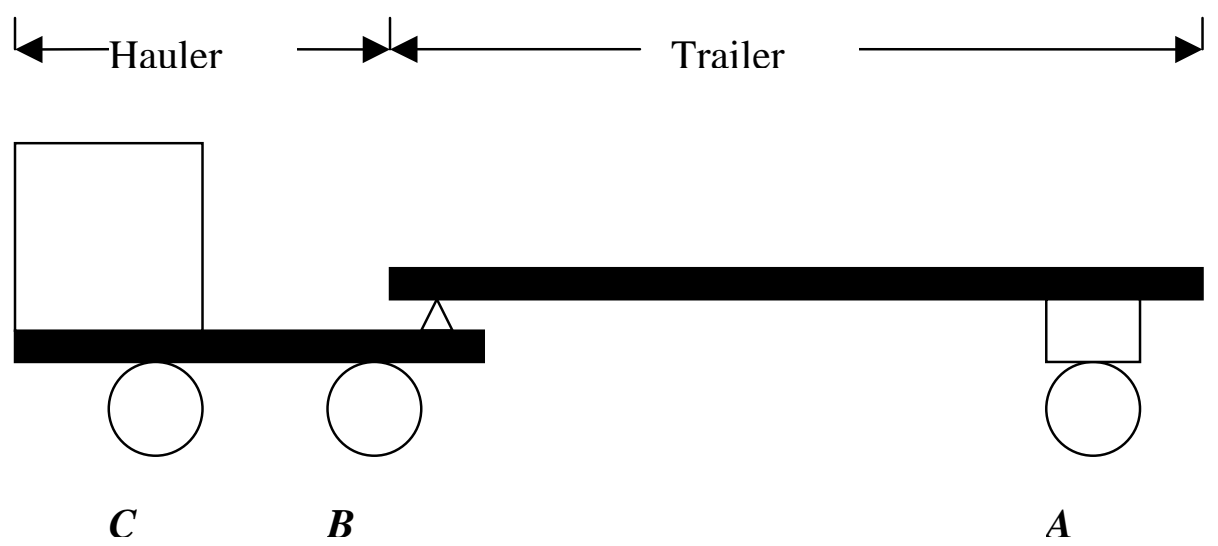

Figure 1: Points of axle weights in hauler-trailer rig

The nature of the problem precludes the possibility of minimizing the load on each individual axle. This follows because a reduction in the force applied to one axle automatically increases the weight on another. A realistic approach for the problem calls for determining the distribution of packs on the trailer that will result in a "compromise" solution for axle weights. This point will be developed further after the details of the problem have been presented.

Figure 2 provides a schematic top view of a trailer. The length of the trailer is divided into zones whose number and boundaries vary depending on the mix of ordered packs. The width of the trailer is divided symmetrically between right and left sides, each side with an equal number of "slots". A slot in a zone is designed to hold one pack of plates.

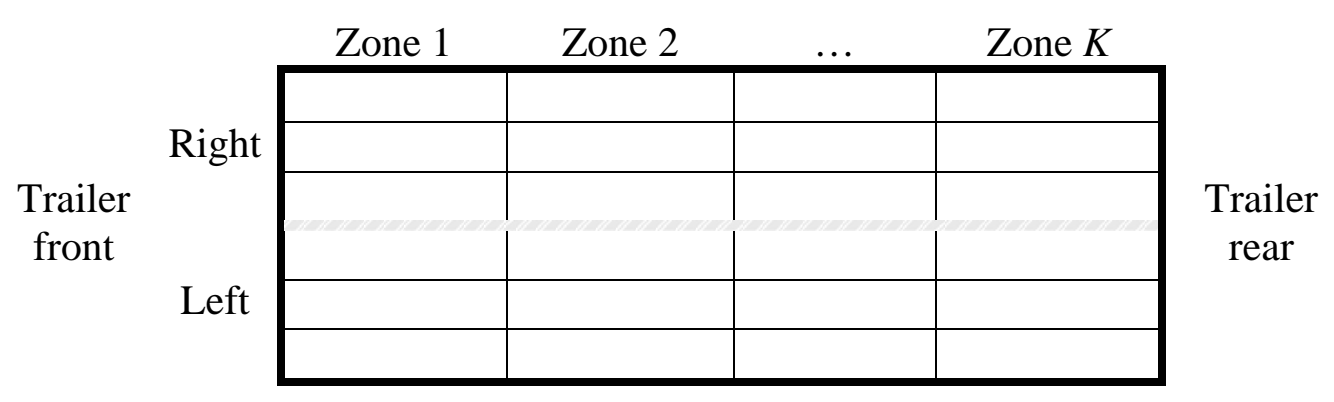

Figure 2: Schematic top view of trailer zones and slots 


\section{CALCULATION OF AXLE WEIGHTS}

The analysis in this section follows the exact procedure suggested in Brits and Conradie [1]. It is repeated here for continuity.

Weights (loads) on axles can be determined by applying the following static equilibrium equations, first to the trailer and then to the hauler:

1. Sum of forces $=0$.

2. Sum of moments $=0$.

Figure 3 provides the free body diagram for the trailer. For convenience, the trailer has three zones, but the analysis can be extended readily to any number of zones. The forces, in $\mathrm{kg}$, acting on the trailer are

$$
\begin{aligned}
& f_{k}=\text { Weight of glass packs in zone } k, k=1,2,3 \\
& f_{t}=\text { Trailer weight } \\
& R=\text { Reaction force at fifth wheel (hinge) } \\
& f_{A}=\text { Reaction force at trailer (rear) axle }
\end{aligned}
$$

The different distances (in meters) in the figure are known from the geometry of the trailer.

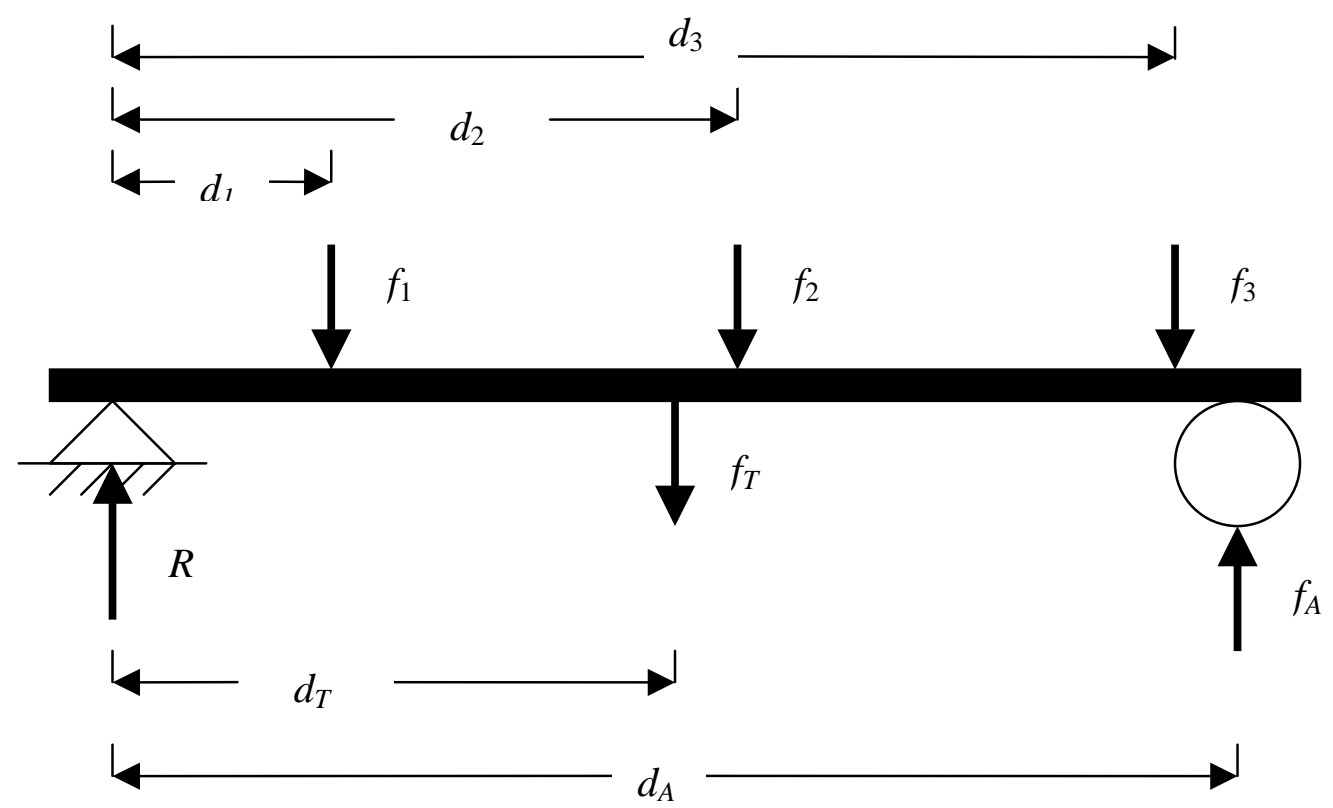

Figure 3: Trailer Free Body Diagram

The static equilibrium equations for the trailer are

$$
\begin{aligned}
& f_{1}+f_{2}+f_{3}+f_{T}=R+f_{A} \\
& f_{1} d_{1}+f_{2} d_{2}+f_{3} d_{3}+f_{T} d_{T}-f_{A} d_{A}=0
\end{aligned}
$$


We have two equations in two unknowns, $R$ and $f_{c}$, which yield the solution

$$
\begin{aligned}
& f_{A}=\frac{1}{d_{A}}\left(f_{1} d_{1}+f_{2} d_{2}+f_{3} d_{3}+f_{T} d_{T}\right) \\
& R=f_{1}+f_{2}+f_{3}+f_{T}-f_{A}
\end{aligned}
$$

Next, we apply similar analysis to the hauler free body diagram in Figure 4. The weight of the hauler is represented by $f_{H}$ and the impact of the trailer forces on the hauler is given by the reaction force $R$ computed in equation (2) above. The associated equilibrium equations are

$$
\begin{aligned}
& f_{B}+f_{C}=R+f_{H} \\
& f_{H} d_{H}+R d_{R}-f_{B} d_{B}=0
\end{aligned}
$$

Solving for $f_{B}$ and $f_{C}$, we get

$$
\begin{aligned}
& f_{B}=\frac{1}{d_{B}}\left(f_{H} d_{H}+R d_{R}\right) \\
& f_{C}=R+f_{H}-f_{B}
\end{aligned}
$$

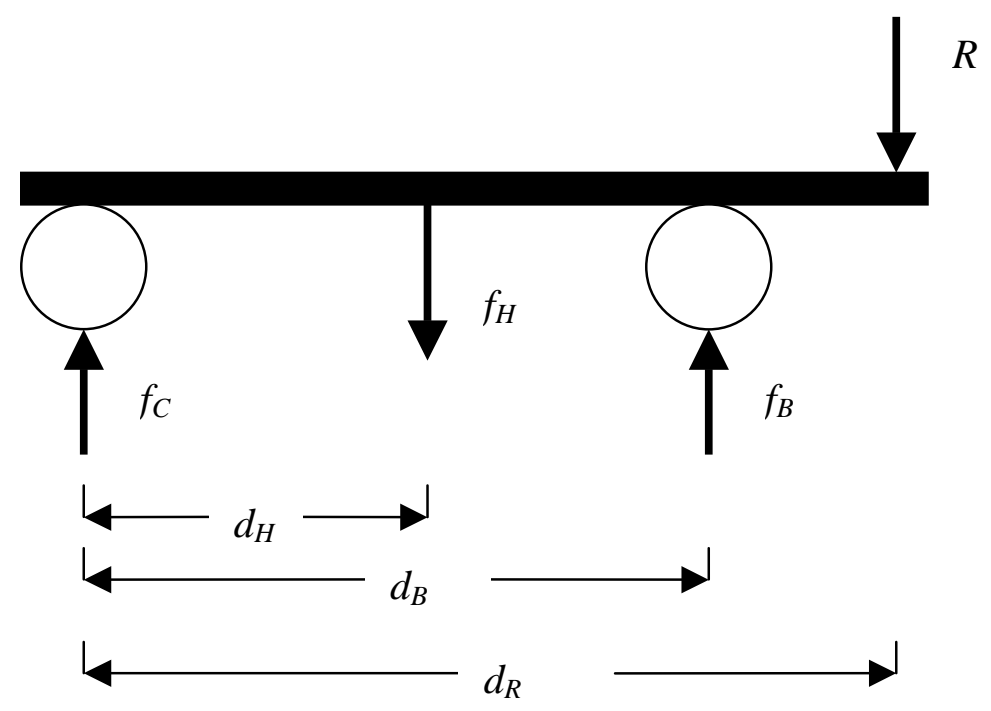

Figure 4: Hauler Free Body Digram

Equations (1), (3), and (4) provide the solution for the reaction forces, $f_{A}, f_{B}$, and $f_{C}$, acting on axles $A, B$, and $C$ of the hauler-trailer rig. Letting $w_{A}, w_{B}$, and $w_{C}$ represent the dead weights of the axles themselves, the total weights (in $\mathrm{kg}$ ) applied to the axles are then computed as

$$
\begin{aligned}
& W_{A}=f_{A}+w_{a} \\
& W_{B}=f_{B}+w_{B} \\
& W_{C}=f_{C}+w_{C}
\end{aligned}
$$


These are the weights that will be used to enforce government regulations.

\section{DEVELOPMENT OF THE MATHEMATICAL MODEL:}

We consider the situation in which an order mix of $I$ types of glass packs are placed in $K$ zones with each zone holding $J$ slots. The axle weights given in equations (5), (6), and (7) can be expressed in terms of the original forces, $f_{H}, f_{T}$, and $f_{k}, k=1,2, \ldots, K$, as follows:

$$
\begin{aligned}
& W_{A}=w_{A}+\frac{1}{d_{A}} \sum_{k=1}^{K} f_{k} d_{k}+f_{T} d_{T} \\
& W_{B}=w_{B}+\frac{1}{d_{B}}\left(f_{H} d_{H}+R d_{R}\right) \\
& W_{C}=w_{C}+R\left(1-\frac{d_{R}}{d_{B}}\right)+f_{H}\left(1-\frac{d_{H}}{d_{B}}\right)
\end{aligned}
$$

where

$$
R=\sum_{k=1}^{K} f_{k}\left(1-\frac{d_{k}}{d_{A}}\right)-\frac{1}{d_{A}}\left(f_{T} d_{T}\right)
$$

Define

$$
\begin{aligned}
& x_{i j k}=\left\{\begin{array}{l}
1, \text { if pack } i \text { is assigned to slot } j \text { in zone } k \\
0, \text { otherwise }
\end{array}\right. \\
& w_{i}=\text { weight per pack of glass type } i
\end{aligned}
$$

Glass weights applied to zone $\mathrm{k}$ of the trailer can then be computed in terms of $x_{i j k}$ as

$$
f_{k}=\sum_{i=1}^{I} w_{i}\left(\sum_{j=1}^{J} x_{i j k}\right), k=1,2, \ldots, K
$$

All the remaining elements in (8), (9), and (10) are known.

Having expressed axle weights in terms of the variable $x_{i j k}$, we now pay attention to constructing the optimisation model. The main purpose of the model is to assign packs to slots in a manner that the axle weights $W_{A}, W_{B}$, and $W_{C}$ will remain within the limits set by government regulations. In other words, we cannot just include these limits as simple constraints of the form $W_{A} \leq L_{A}, W_{B} \leq L_{B}$, and $W_{C} \leq L_{C}$ because the problem may not have a feasible solution. Ideally, then, we would like to determine the values of $x_{i j k}$ that will reduce the individual axle weights as much as possible. If the resulting minimum weights meet government regulations, then the solution is at hand. Else, the size of the order mix must be reduced and a new solution must be attempted. The difficulty with this "idealized" solution is that the nature of the problem will not allow the minimization of individual axle weights because, as stated earlier, they are interdependent, in the sense that a decrease in one load automatically increases another.

A formulation that comes close to minimizing the individual axle weights is to find a solution that minimizes the largest of the axle weights. This formulation has the advantage of concentrating on the most extreme of all three weights. Mathematically, the objective function is expressed as 


$$
\operatorname{minimize~} \mathrm{z}=\max \left\{W_{A}, W_{B}, W_{C}\right\}
$$

This function can be linearised readily by using the following standard substitution. Let

$$
\mathrm{y}=\max \left\{W_{A}, W_{B}, W_{C}\right\}
$$

Then the objective function can be expressed as

$$
\text { maximize } z=y
$$

subject to

$$
\begin{aligned}
& W_{A} \leq y \\
& W_{B} \leq y \\
& W_{C} \leq y
\end{aligned}
$$

Keep in mind that the resulting solution, while in a sense giving the most advantageous assignment of packs to slots, does not guarantee that weight limits will be met. If this happens, the order size must be reduced and a new solution attempted. We will show shortly how information can be obtained from the solution to give an idea of an estimate of the amount by which an order size may be reduced to satisfy the weight limits.

We now turn our attention to the development of the constraints of the model. These constraints deal with

1. At most one pack per slot.

2. Limits on zone weight.

3. Number of packs (by type) in the order mix.

4. Packs are pushed toward the centre in each zone to avoid trailer tipping.

5. Pack dimension match to zone dimensions.

The first three constraints are essential and must be included in the model. Constraint 4, though included in the model, is really not crucial, mainly because the entire glass weight in zone $k$ is represented by $f_{k}$ which is not a function of the location of specific slots in the zone. One will then presume that whatever the solution, the actual loading of the trailer in a zone will automatically move the packs toward the centre. Constraint 5 is straightforward and will not be included in the model for simplicity.

Define

$L_{k}=$ glass load weight limit in zone $k, k=1,2, \ldots, K$

$L_{A}=$ allowable weight limit on axle $A$ (trailer rear axle)

$L_{B}=$ allowable weight limit on axle $B$ (hauler rear axle)

$L_{C}=$ allowable weight limit on axle $C$ (hauler front axle)

$w_{A}=$ weight of axle $A$

$w_{B}=$ weight of axle $B$

$w_{C}=$ weight of axle $C$

Constraints (1) through (4) are expressed mathematically as 


$$
\begin{aligned}
& \sum_{i=1}^{I} x_{i j k} \leq 1, j=1,2, \ldots, J ; k=1,2, \ldots, K \\
& \sum_{i=1}^{I} w_{i} \sum_{j=1}^{J} x_{i j k} \leq L_{k}, k=1,2, \ldots, K \\
& \sum_{j=1}^{J} \sum_{k=1}^{K} x_{i j k}=N_{i}, i=1,2, \ldots, I \\
& \sum_{i=1}^{I} x_{i j k} \leq \sum_{i=1}^{I} x_{i, j+1, k}, j=1,2, \ldots \frac{J}{2}-1 ; k=1,2, \ldots, K \\
& \sum_{i=1}^{I} x_{i j k} \geq \sum_{i=1}^{I} x_{i, j+1, k}, j=\frac{J}{2}, \frac{J}{2}+1, \ldots, J-1 ; k=1,2, \ldots, K
\end{aligned}
$$

\section{MODEL SOLUTION WITH AMPL}

The AMPL code in Figure 5 is self-explanatory because it closely follows the notation used in the development of the mathematical model. The code checks for the initial feasibility of the data to ensure that the number of packs in an order mix does not exceed the number of slots specified by the designated zones of the trailer. Else, the code will print out (to output file aa.txt) one of two types of solution:

1. A feasible solution in which all zone and axle weight limits are satisfied.

2. An infeasible solution if any zone or axle weight limits are exceeded.

In the second case, the cause and quantification of the source(s) of infeasibility are given. This information may be used to modify the number and type of packs in an order with the objective of eliminating infeasibility. The model is then re-run and the resulting output is rechecked for feasibility.

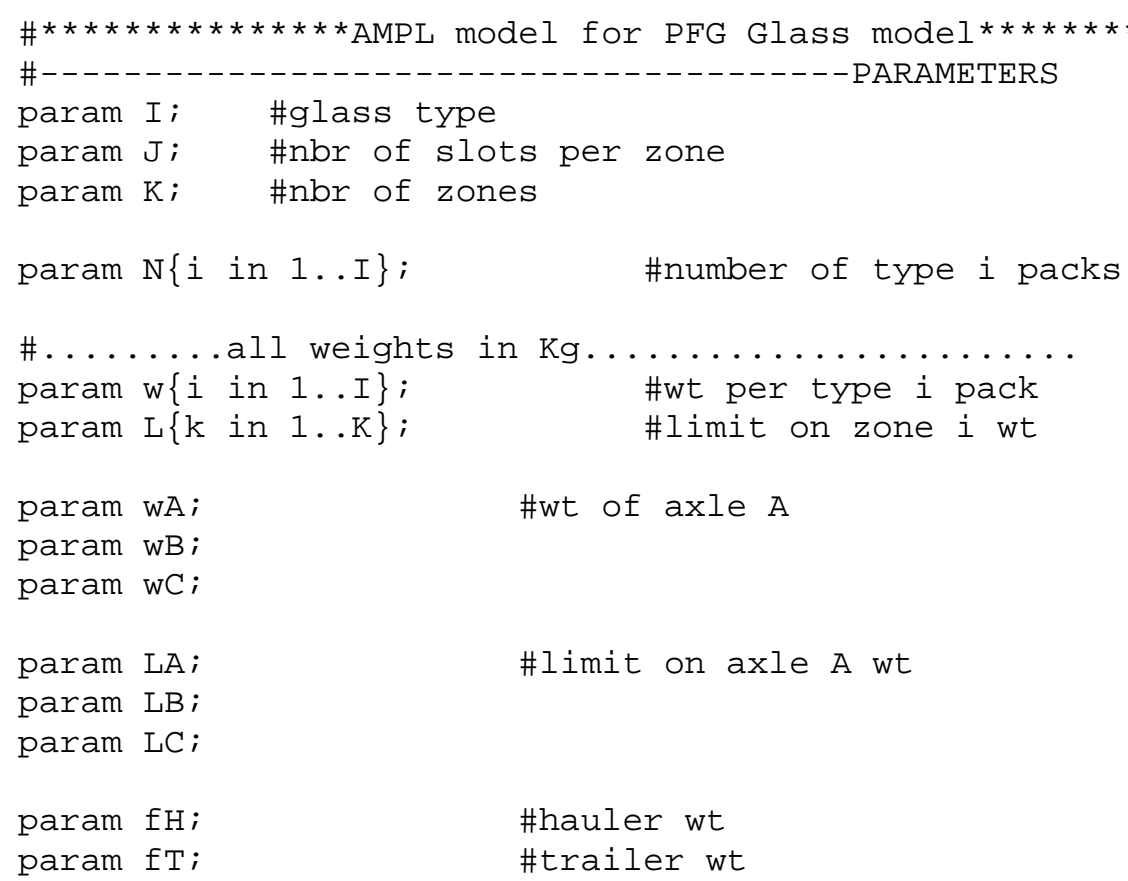




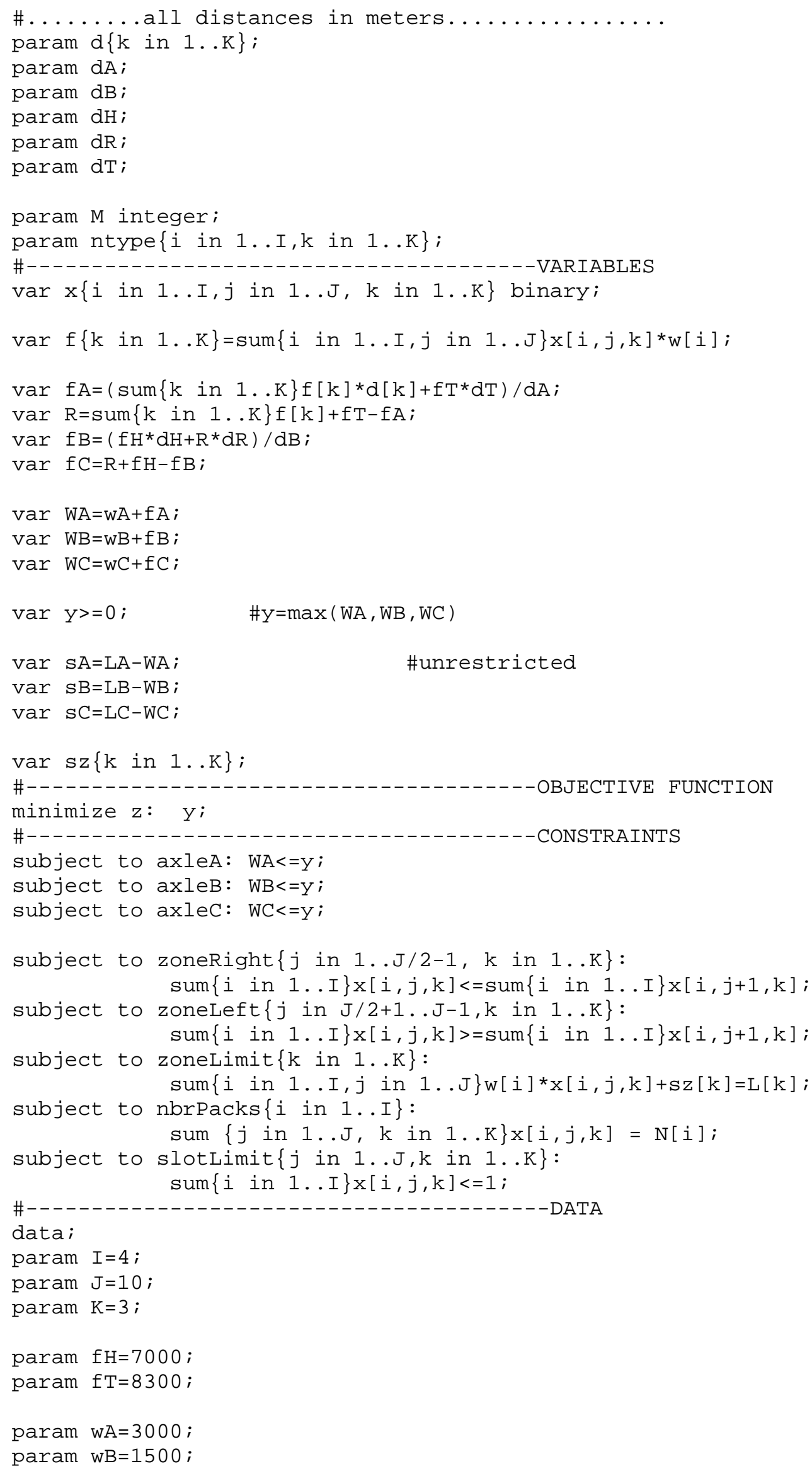




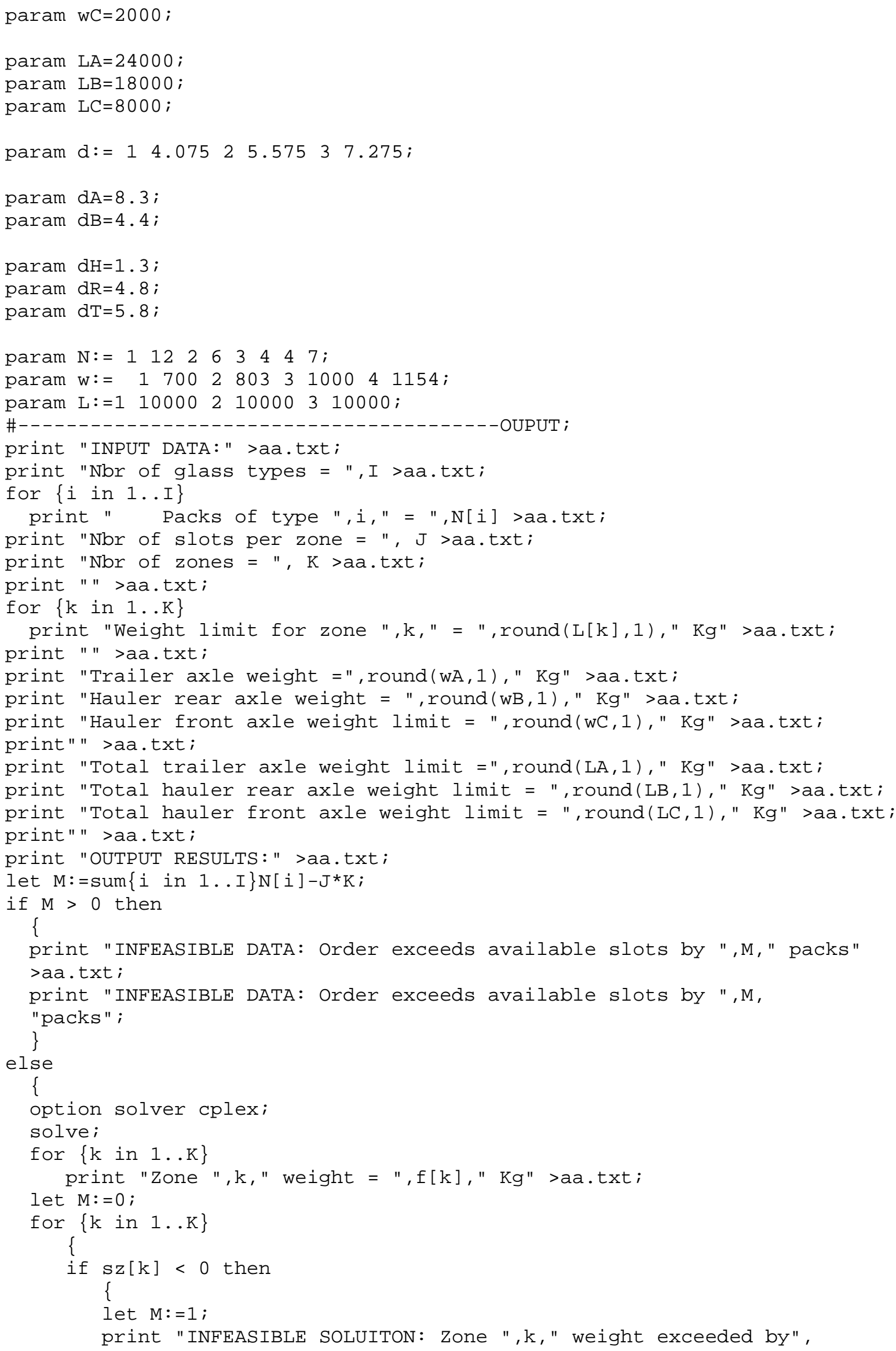




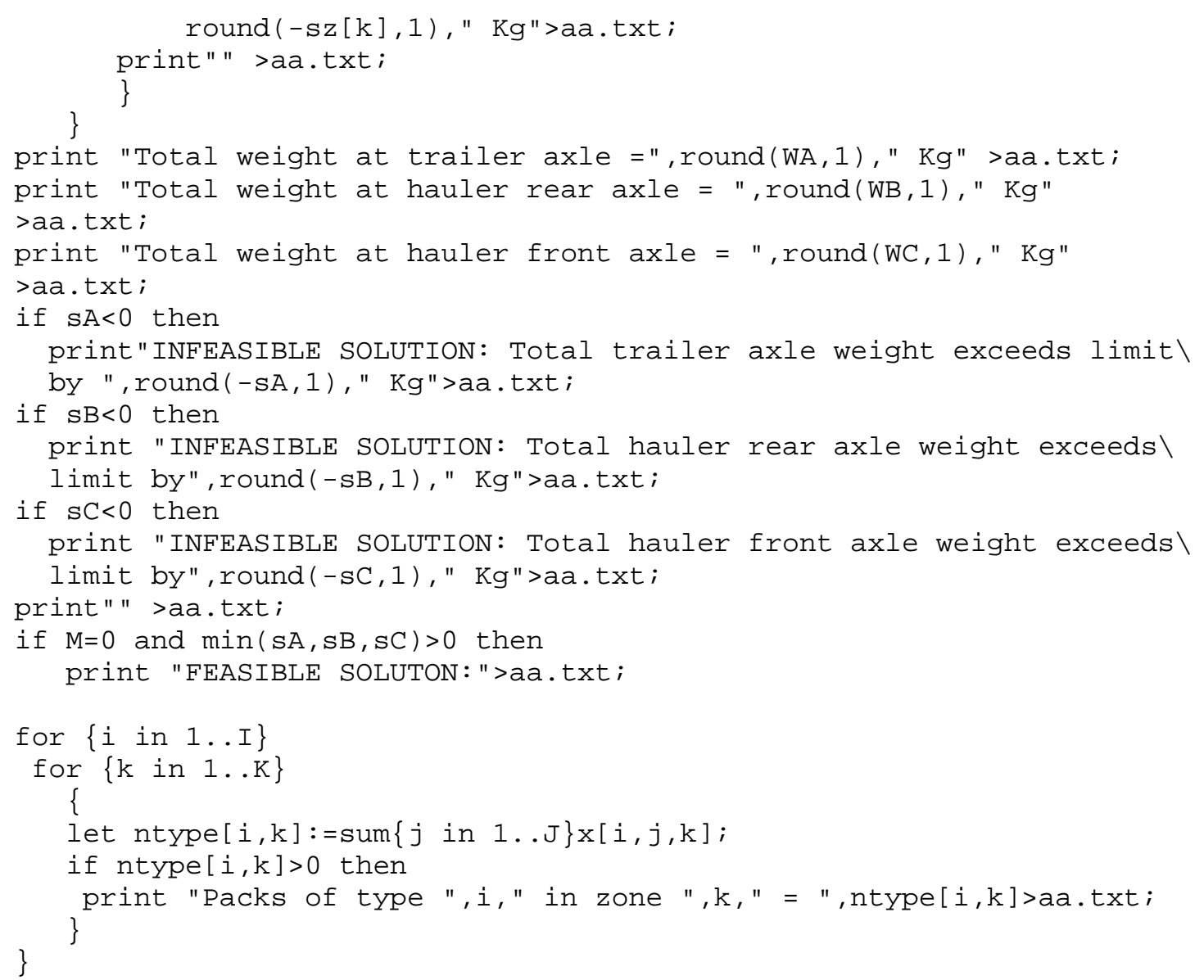

Figure 5 AMPL model of the PFG glass problem

Figure 6 provides the output of AMPL for the set of data given in Figure 5. The output results section provides all the information needed regarding the solution. If the solution happens to be infeasible, causes of infeasibility are given so that the user can make informed decisions about the order mix under consideration.

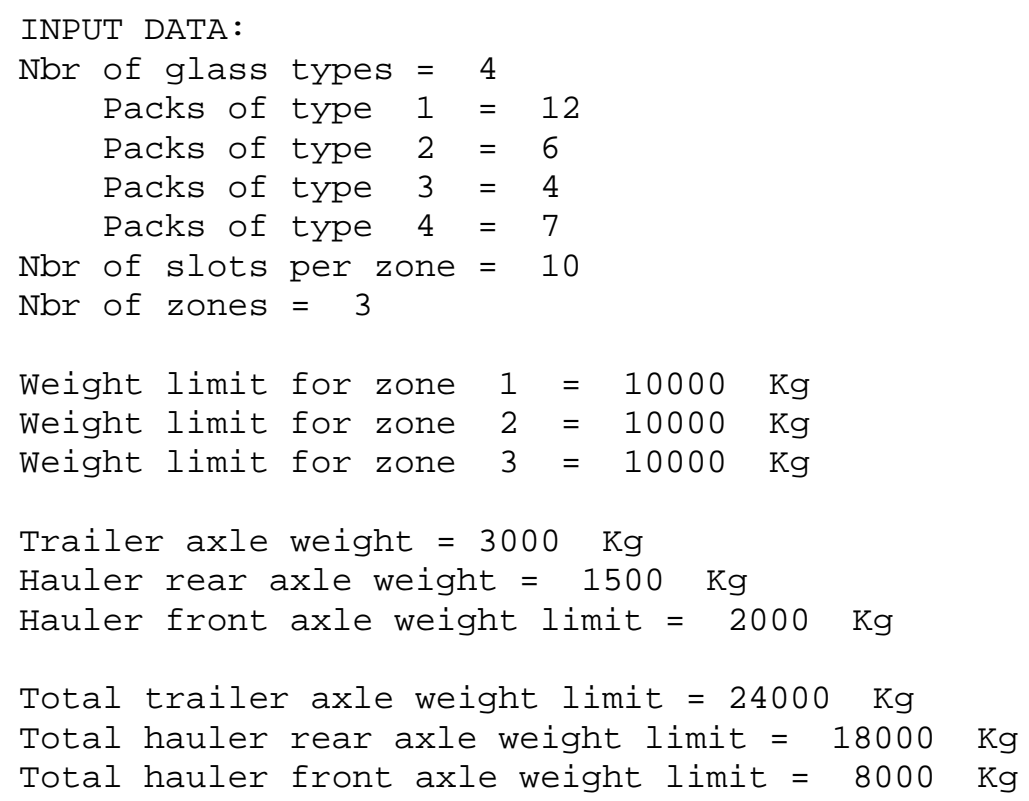




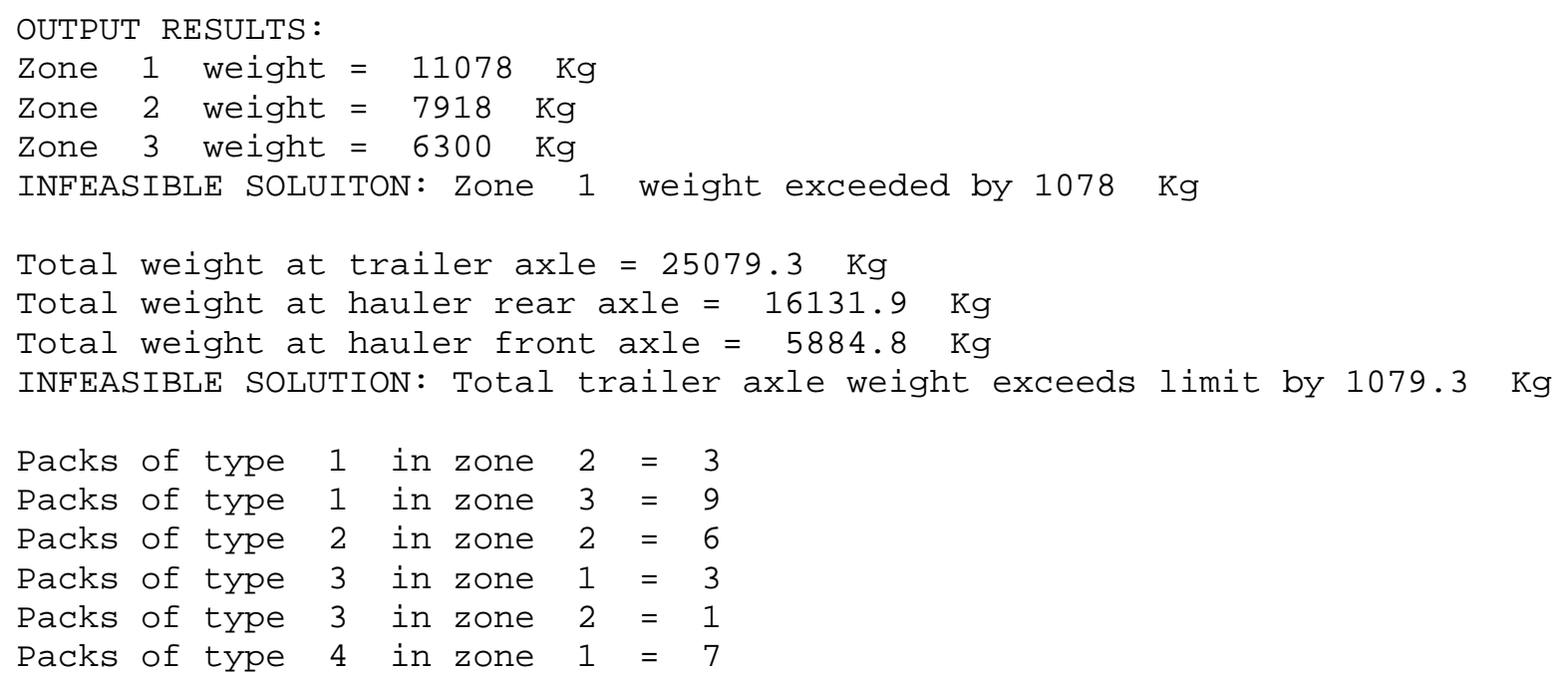

Figure 6: AMPL output for the data in Figure 5

\section{CONCLUSIONS}

The model presented in this article has the advantage of incorporating axle weights directly in the optimisation model. The resulting solution provides the most effective way to load an order on the trailer while keeping axle loads as low as possible. If the resulting solution does not meet regulations, the model provides information that can be used as guide to adjust the contents of an order mix opportunely in order to meet government limits.

\section{REFERENCES}

[1] R. Brits and P.J. Conradie, "A model to Optimize Payloads at PFG Building Glass," South Africa Journal of Industrial Engineering, Vol. 14, No. 1, 2003, pp. 1-16.

[2] Taha, H., Operations Research: An Introduction, $7^{\text {th }}$ Edition, Prentice Hall, 2002.

[3] Taha, H., Integer Programming: Theory, Applications, and Computations, Academic Press, 1975. 